\title{
ANALISIS KELAYAKAN INVESTASI \\ APLIKASI NAVISION BAGIAN PRODUKSI MENGGUNAKAN METODE INFORMATION ECONOMICS PADA PT. FRINA LESTARI NUSANTARA
}

\author{
Hudiarto; Diana Sari; Kresna Hutama; Rosalia Yudanto \\ Jurusan Sistem Informasi, Fakultas Ilmu Komputer, Binus University \\ Jl. KH. Syahdan No. 9, Palmerah, Jakarta Barat 11480. \\ Hudiarto@binus.edu
}

\begin{abstract}
Investments in system and information technology applied in a company sometimes do not provide benefits comparing to the cost. Therefore, we propose to PT. Frina Lestari Nusantara to measure the economic benefits gained from the implementation of Microsoft Dynamics NAV (Microsoft Navision) using Information Economics method, so that later on the benefits obtained from the feasibility assessment on the applied Navision can be provided. The methodology used is field research and literature study. The Field research is in form of observations of product selling process, analysis of the data obtained, direct interviews and questionnaire distribution to the relevant sections. The literature study is used to find, collect and study the needed data and information using references from various media and sources. From the results it is concluded that the implementation of Navision application executed so far is pretty decent to be implemented and helps improve the company's performance.
\end{abstract}

Keywords: Microsoft Dynamic NAV (Microsoft Navision), Information Economics, investments, information system, information technology.

\begin{abstract}
ABSTRAK
Investasi sistem dan teknologi informasi yang diterapkan pada suatu perusahaan terkadang tidak memberikan manfaat yang sebanding dengan biaya yang dikeluarkan. Oleh karena itu, diusulkan pada PT. Frina Lestari Nusantara untuk mengukur manfaat ekonomis yang didapat dari aplikasi Microsoft Dynamic NAV (Microsoft Navision) menggunakan metode Information Economics sehingga nantinya dari manfaat-manfaat yang diperoleh tersebut penilaian kelayakan atas aplikasi Navision yang diterapkan dapat diberikan. Metodologi yang digunakan adalah penelitian lapangan dan studi kepustakaan. Metode penelitian lapangan berupa observasi terhadap proses penjualan produk, analisis terhadap data yang diberikan, wawancara secara langsung dengan bagian yang terkait langsung dan pemberian kuesioner kepada bagian yang terkait. Metode studi kepustakaan digunakan untuk mencari, menghimpun dan mempelajari data dan informasi yang dibutuhkan dengan menggunakan referensi dari berbagai media dan sumber. Dari hasil penelitian diperoleh kesimpulan bahwa penerapan aplikasi Navision yang telah dijalankan selama ini cukup layak diimplentasikan dan turut meningkatkan kinerja perusahaan.
\end{abstract}

Kata kunci: Microsoft Dynamic NAV (Microsoft Navision), Information Economics, investasi, sistem informasi, teknologi informasi 


\section{PENDAHULUAN}

PT. Frina Lesteri Nusantara (FLN) merupakan sebuah perusahaan yang bergerak dibidang variasi mobil di mana dalam menjalankan proses bisnisnya perusahaan ini dibantu oleh beberapa kantor cabang yang tersebar beberapa lokasi. Oleh karenanya, PT. FLN merasa perlu melakukan pengembangan terhadap teknologi informasi yang diharapkan dapat mendukung proses bisnis perusahaan agar menjadi lebih baik dan data yang ada dapat saling terintegrasi. Untuk itu, PT. FLN menginvestasikan aplikasi teknologi informasi yang bernama Microsoft Dynamic NAV (Navision).

Implementasi Navision pada PT. FLN mengeluarkan biaya yang tidak sedikit. Oleh karena itu, dibutuhkan metode perhitungan untuk menganalisis serta mengukur manfaat dari penerapan aplikasinya. Dalam hal ini penulis menggunakan metode Information Economics yang bertujuan untuk menganalisis kelayakan investasi Navision pada PT. FLN. Metode yang akan digunakan untuk menganalisis manfaat ini adalah metode Information Economics. Information Economics merupakan suatu metode yang digunakan untuk menganalisis manfaat dari penerapan teknologi informasi di dalam perusahaan yang bertujuan untuk memprioritaskan investasi teknologi informasi yang akan diterapkan agar investasi tersebut sebanding dengan manfaat yang diperoleh dengan sejumah uang yang dikeluarkan, dalam hal ini berupa investasi pada aplikasi dan hardware.

\section{Rumusan Masalah}

Beberapa masalah yang diharapkan akan terjawab setelah penulisan skripsi ini selesai sebagai berikut: (1) Manfaat apa saja yang diperoleh pihak PT. FLN dengan adanya investasi aplikasi Navision? (2) Apakah aplikasi Navision ini layak untuk diimplementasikan pada PT. FLN?

\section{Ruang Lingkup}

Untuk memperjelas penelitian yang dilakukan, ruang lingkup makalah ini dibatasi sebagai berikut: (1) Analisis yang dilakukan hanya pada pengimplementasian aplikasi Navision bagian produksi pada kantor pusat PT. FLN; (2) Analisis dilakukan dengan menggunakan langkah-langkah yang ada dalam metode Information Economics.

\section{Tujuan}

Tujuan dari penelitian adalah: (1) Untuk mengukur manfaat ekonomis dari implementasi aplikasi Navision pada PT. FLN; (2) PT. FLN akan mengetahui manfaat yang didapat baik tangible, dan intangible dengan menerapkan Navision pada PT. FLN dengan menggunakan metode Information Economics.

\section{Manfaat}

Memberikan informasi kepada pihak PT. FLN untuk menentukan apakah investasi aplikasi Navision yang dilakukan bermanfaat atau tidak bermanfaat.

\section{METODE}

Penelitian terhadap implementasi aplikasi Navision pada PT. FLN ini menggunakan metode: (1) Penelitian lapangan berupa observasi terhadap proses penjualan produk, analisis terhadap data yang diberikan, wawancara secara langsung dengan bagian yang terkait langsung dan pemberian 
kuesioner kepada bagian yang terkait; (2) Studi kepustakaan digunakan untuk mencari, menghimpun dan mempelajari data dan informasi yang dibutuhkan dengan menggunakan referensi dari berbagai media dan sumber.

\section{Tinjauan Pustaka}

\section{Information Economics}

Menurut Parker et al. (1988, p.101), “Information Economics merupakan alat yang digunakan untuk mengevaluasi investasi teknologi informasi (TI) yang terdapat dalam perusahaan. Information Economics terdiri dari peralatan untuk menganalisis dan mengukur biaya (cost) dan nilai (value). Information Economics ini berhubungan erat dengan evaluasi risiko dan masalah investasi lainnya dalam proses pengambilan keputusan. Information Economics menentukan keputusan investasi yang berpusat pada aplikasi proyek dan arsitektur sistem informasi.”

Awalnya, Information Economics adalah sebuah kumpulan dari peralatan komputasional untuk mengkuantifikasikan manfaat-manfaat dan biaya-biaya proyek sistem informasi (Parker et al., 1988, p.5). Ini adalah peran tradisional dari analisis biaya manfaat. Information Economics melihat jauh ke dalam analisis biaya-manfaat untuk memasukan nilai yang didasarkan pada kinerja bisnis untuk menangani hal-hal yang memiliki dampak strategis terhadap perusahaan. Information Economics juga melihat ke dalam infrastruktur teknologi informasi (investasi persediaan dalam infrastruktur).

Selanjutnya, Information Economics adalah sebuah proses pembuatan keputusan. Setiap investasi (pemrograman, aplikasi, perangkat keras) harus dijustifikasi, tetapi setiap investasi yang potensi memiliki karakteristik yang unik dan berbeda terhadap nilai, biaya dan risikonya.

Lingkup dari Information Economics terdiri dari biaya-biaya, alat-alat penilaian dan ukuranukuran. Hal tersebut berhubungan dengan evaluasi risiko dan isu-isu investasi lainnya dalam pembangunan persetujuan, proses pengambilan keputusan. Investasi Information Economics berbicara keputusan-keputusan investasi mengenai proyek-proyek aplikasi spesifik dan arsitektur sistem informasi, (Parker et al., 1988, p.103). Lima teknik justifikasi finansial yang digunakan untuk mengukur dan menilai kekuatan aplikasi teknologi informasi adalah: (1) analisis biaya manfaat tradisional; (2) value linking; (3) value acceleration; (4) value restructuring; (5) innovation valuation.

Teknik-teknik tersebut menunjukkan teknik-teknik justifikasi finansial yang diterapkan dalam Information Economics untuk perhitungan ROI, (Parker et al., 1988, p103).

\section{Analisis Business Domain dan Technology Domain}

Menurut Parker et al., (1988, p.75) "Secara Information Economics, analisis dua domain dapat diperluas menjadi dua model. Dua model umum tersebut yaitu substitusi nilai (value) untuk keuntungan dan membagikan biaya sebenarnya dari jasa yang ada dalam domain teknologi yang diperoleh dari pendistribusian biaya dari keseluruhan biaya yang ada ke domain bisnis.”

\section{Nilai dan Risiko Domain Bisnis}

Dalam bukunya, Parker et al. (1988, p.144) mengatakan bahwa nilai dan biaya tidak digambarkan secara pasti dalam perhitungan simple ROI, hanya ada beberapa yang khusus untuk domain bisnis dan yang lainnya untuk domain teknologi. Konsep dari nilai didasarkan pada kinerja bisnis dan biaya didasarkan pada risiko bisnis dan teknis, perlengkapan dari teknik baru ini digunakan untuk menetapkan simple ROI. 
Terdapat lima faktor utama dalam domain bisnis yang berada diluar perhitungan ROI sederhana yaitu strategic match, competitive advantage, management information support, competitive response, dan project or organizational risk. Keempat elemen pertama bernilai positif sedangkan organizational risk bernilai negatif. Pada domain teknologi terdapat empat faktor, yaitu strategic IS architecture, definitional uncertainity, technical uncertainity, dan IS infrastructure risk. Hanya terdapat satu elemen yang bernilai positif yaitu strategic IS architecture sedangkan yang lain bernilai negatif.

Untuk menghitung simple ROI digunakan tiga set lembar kerja (Parker et al., 1988, p.95-97), yaitu: Lembar Kerja Biaya Pengembangan, Lembar Kerja Beban Yang Sedang Berjalan, dan Lembar Kerja Dampak Ekonomis.

Lembar Kerja Biaya Pengembangan (Gambar 1) terdiri dari lima kategori: usaha pengembangan, perangkat keras baru, pembelian piranti lunak baru, pelatihan pemakai, dan biayabiaya lainnya. Usaha pengembangan meliputi penambahan biaya sistem dan pemrograman, serta tambahan dukungan staf, seperti administrasi data. Perangkat keras baru meliputi biaya tambahan untuk komputer, printer, dan komunikasi. Piranti lunak baru termasuk setiap pembelian atau penyewaan piranti lunak yang baru, dan pelatihan terdiri dari biaya pengajaran dan juga kurva belajar.

\begin{tabular}{|c|c|c|}
\hline & & Tahun ke-1 \\
\hline \multirow[t]{4}{*}{ A } & Usaha pengembangan & \\
\hline & $\begin{array}{l}\text { 1. Peningkatan sistem dan pemrograman } \\
\text { (Contoh: perkiraan jumlah dari pada \$ } \\
\text { xxx/hari) }\end{array}$ & \\
\hline & 2. Peningkatan staff support & \\
\hline & (Contoh: data administration pada \$xxx/hari) & \\
\hline \multirow[t]{3}{*}{ B } & Perangkat keras Baru & \\
\hline & 1. Terminal, printer, komunikasi & \\
\hline & 2. lainnya & \\
\hline \multirow[t]{3}{*}{ C } & Pembalian piranti lunak baru, jika ada & \\
\hline & 1. paket software aplikasi & \\
\hline & 2. lainnya & \\
\hline $\mathrm{D}$ & Pelatihan user & \\
\hline \multirow[t]{2}{*}{$\mathrm{E}$} & Lainnya & \\
\hline & TOTAL & \\
\hline
\end{tabular}

Gambar 1. Lembar kerja biaya pengembangan (Parker et al., 1988, p.96).

Lembar Kerja Beban yang Sedang Berjalan (Gambar 2) terdiri dari enam kategori, yaitu: pemeliharaan aplikasi piranti lunak, biaya penyimpanan data tambahan, penambahan komunikasi, penyewaan perangkat keras dan piranti lunak baru, persediaan dan lain-lain. Biaya pemeliharaan aplikasi piranti lunak diperoleh dari memperkirakan jumlah hari pengembangan (dari lembar kerja biaya pengembangan). Rasio pemeliharaan diaplikasikan terhadap hari pengembangan dan dikalikan 
dengan tarif pemeliharaan sehari-hari. Hasilnya adalah biaya pemeliharaan aplikasi piranti lunak. Biaya penyimpanan data tambahan didapat dari perkiraan jumlah megabyte terhadap perkiraan biaya per megabyte. Biaya komunikasi tambahan adalah biaya yang berhubungan dengan kabel, pesan dan sebagainya. Biaya penyewaan perangkat keras dan piranti lunak baru dapat diidentifikasi sama mudahnya dengan persediaan dan biaya lain-lainnya.

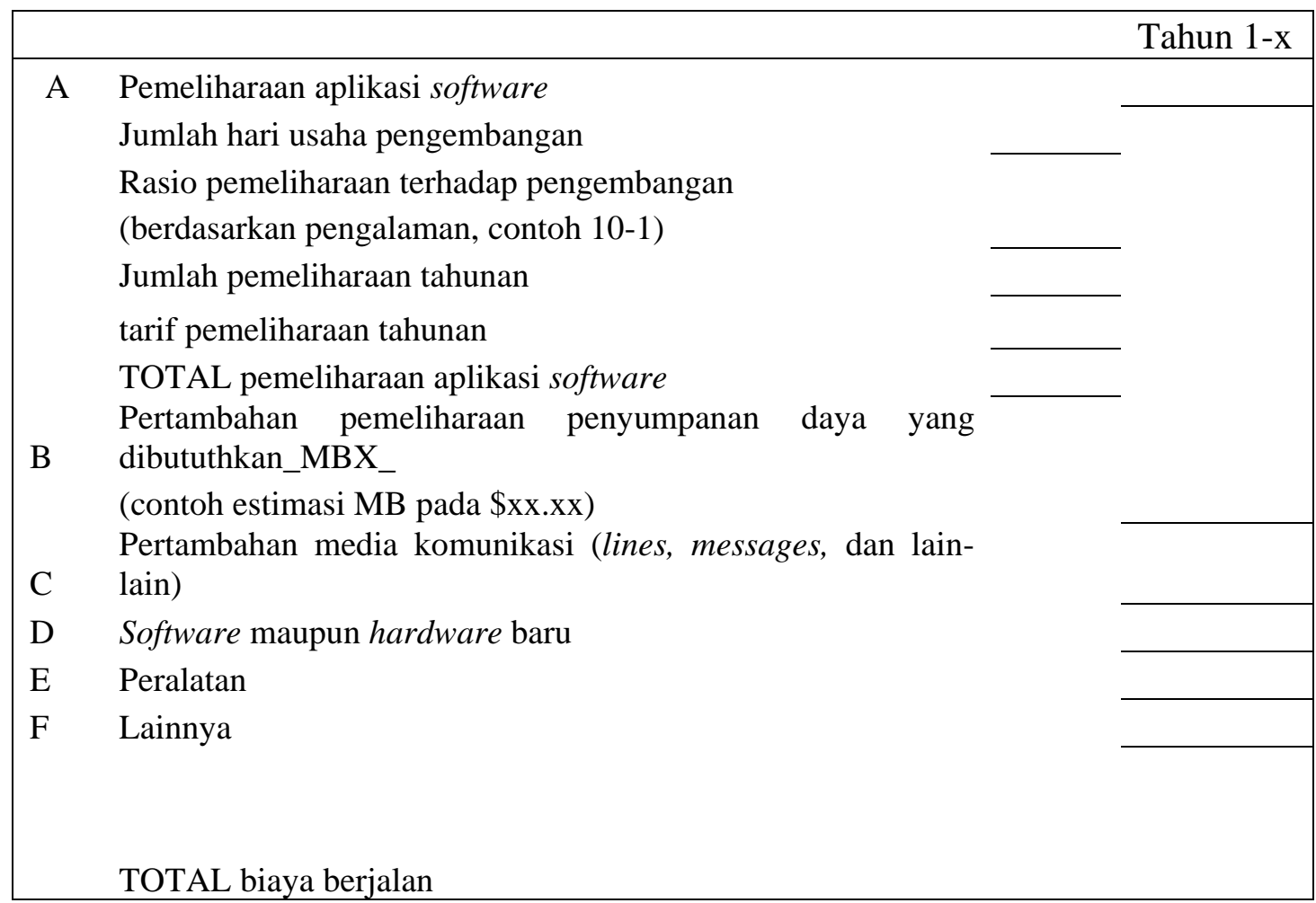

Gambar 2. Lembar kerja beban yang sedang berjalan (Parker et al., 1988, p.96).

Lembar kerja dampak ekonomis (Gambar 3) meringkas dampak ekonomis suatu proyek. Penilaian skor dampak ekonomis didasarkan pada hubungan garis lurus untuk menghitung simple ROI dari lima tahun periodik arus kas bersih proyek yang disusulkan. Pertama-tama, diperlukan investasi bersih dan elemen ini telah dihasilkan dari lembar kerja biaya pengembangan. Kedua, diperlukan arus kas tahunan. Ini didapat dari bila ada manfaat ekonomis bersih dari pemakai atau sponsor, lalu dikurangi dengan biaya operasional. Perbedaannya, pendapatan sebelum pajak dikurangi dengan pengeluaran yang sedang berjalan, lalu didapatlah arus kas bersih per tahun. Simple ROI dihitung dengan membagi rata-rata arus kas bersih selama lima tahun dengan investasi bersih yang dibutuhkan.

\section{HASIL DAN PEMBAHASAN}

Microsoft Dynamic NAV (Microsoft Navision) adalah suatu program yang menyediakan kemudahan menjalankan proses bisnis. Navision merupakan program yang dapat disesuaikan dengan kebutuhan prusahaan sesuai divisinya dan dapat dipelihara dengan baik sehingga mengurangi gangguan sesuai dengan pertumbuhan bisnis. 


\begin{tabular}{|c|c|c|c|c|c|c|}
\hline \multicolumn{7}{|c|}{$\begin{array}{l}\text { A. Net Investment Required (dari Devlopment Cost Worksheet) } \\
180,856 \\
\text { B. Yearly Cash Flow: based on five } 12 \text { months periods following implementation } \\
\text { proposal system }\end{array}$} \\
\hline & & & Year & & & TOTAL \\
\hline & Year 1 & Year 2 & Year 3 & Year 4 & Year 5 & \\
\hline \multicolumn{7}{|l|}{ Net Economics } \\
\hline \multicolumn{7}{|l|}{ Operating Cost } \\
\hline Reduction & 125000 & 125000 & 125000 & 125000 & 125000 & \\
\hline \multicolumn{7}{|l|}{ (-) On-going } \\
\hline Expense & 20912 & 20912 & 20912 & 20912 & 20912 & 520440 \\
\hline Net Cash Flow & 104088 & 104088 & 104088 & 104088 & 104088 & $58 \%$ \\
\hline \multicolumn{7}{|c|}{ C. Simple ROI (B: Jumlah tahun: A) } \\
\hline \multicolumn{7}{|c|}{ D. Scoring Economic Impact } \\
\hline & $\begin{array}{l}\text { Score } \\
0 \\
1 \\
2 \\
3 \\
4 \\
5 \\
\end{array}$ & & $\begin{array}{l}\text { Simple ROI } \\
\text { zero or less } \\
1 \%-299 \% \\
300 \%-499 \% \\
500 \%-699 \% \\
700 \%-899 \% \\
\text { over }\end{array}$ & & & \\
\hline
\end{tabular}

Gambar 3. Lembar kerja dampak ekonomis (Parker et al., 1988, p.97).

Navision dapat membatu karyawan lebih produktif, sehingga produktifitas karyawan dapat lebih maksimal, serta mengurangi biaya IT. Selain itu, Navision membantu pengambilan keputusan yang lebih efektif dengan cara: (1) Memperoleh data yang real-time serta keterangan bisnis yang akurat, dan membantu proses bisnis yang lebih efisien; (2) Menyampaikan keterangan kritis yang diperlukan oleh eksekutif dan staff untuk pembuatan keputusan efektif; (3) Lebih teliti dalam profitabilitas proyek atau kontrak; (4) Memberikan pengertian cepat dan mendalam kepada karyawan mengenai pandangan pradefinisi dari data data yang sesuai dengan peranan mereka.

Navision yang akan dikembangkan dan diimplementasikan pada PT. FLN memiliki tujuan sebagai berikut: (1) Memberikan kemudahan dalam mengelola bisnis proses yang dapat disesuaikan dengan bagan organisasi; (2) Memudahkan dalam pernyampaian data dan informasi; (3) Dengan adanya sistem ini, pekerjaan akan lebih mudah dilakukan oleh semua divisi melalui sistem yang sudah 
terkomputerisasi sehingga meningkatkan produktivitas dan kinerja perusahaan; (4) Dengan adanya sistem aplikasi ini maka dapat menyediakan sistem pelaporan yang lengkap, proses pencarian data yang cepat, dan memberikan nilai tambah bagi manajemen, untuk dapat lebih tepat mengelola informasi yang ada.

\section{Biaya Investasi Aplikasi Navision}

Setiap kali mengimplementasikan sebuah sistem, baik itu sistem sederhana maupun sistem yang kompleks pasti dibutuhkan sejumlah biaya untuk mengimplementasikan proyek tersebut yang disebut sebagai biaya berjalan (ongoing expenses). Biaya implementasian ini dapat dibagi menjadi beberapa kategori yaitu perangkat keras, piranti lunak. Total biaya implementasi pada Navision application sebesar US\$ 97.000 atau Rp 970.000 .000 (diasumsikan US\$1 = Rp 10.000,00).

\section{Biaya berjalan Implementasi Aplikasi Navision.}

Selain adanya biaya investasi awal, juga terdapat biaya berjalan yang dihitung selama lima tahun yaitu dari tahun 2007 sampai 2011. Dalam pengembangan sistem ini, biaya berjalan (Tabel 1) yang dikeluarkan meliputi biaya pemeliharaan (maintenance) perangkat keras dan piranti lunak, biaya upgrade, dan biaya lainnya.

Tabel 1

Model Biaya Berjalan

\begin{tabular}{|c|c|c|c|c|c|c|}
\hline $\begin{array}{c}\text { Rincian } \\
\text { biaya }\end{array}$ & $\begin{array}{c}\text { Tahun } \\
2007 \\
\end{array}$ & $\begin{array}{c}\text { Tahun } \\
2008 \\
\end{array}$ & $\begin{array}{c}\text { Tahun } \\
2009 \\
\end{array}$ & $\begin{array}{c}\text { Tahun } \\
2010\end{array}$ & $\begin{array}{c}\text { Tahun } \\
2011 \\
\end{array}$ & Total \\
\hline Maintanance & 250 & 250 & 250 & 250 & 250 & 1.250 \\
\hline Tenaga kerja & 536,40 & 563,22 & 591,38 & 620,95 & 651,99 & $2.963,94$ \\
\hline Lain-lain & 2 & 2 & 2 & 2 & 2 & 10 \\
\hline Total & 788,40 & 815,22 & 843,38 & 872,95 & 903,99 & $4.223,94$ \\
\hline
\end{tabular}

Catatan: Biaya (x Rp. 1 juta)

\section{Formulasi Komponen Information Economics}

Dalam uraian berikut akan dibahas mengenai formulasi dan pengolahan komponen-komponen Information Economics, mulai dari perhitungan biaya dan manfaat tradisional yang menggambarkan dampak dan manfaat ekonomis dalam proyek ini diikuti dengan analisis terhadap Value Linking, Value Acceleration, dan Value Restructuring.

Setelah menjabarkan satu per satu biaya yang dapat dikurangi setelah perusahaan menggunakan application Navision, kita dapat menjumlahkan semua biaya penggurangan biaya tersebut untuk kurun waktu lima tahun. Penjumlahan penggurangan biaya ini dapat juga disebut model IT benefit (Tabel 2).

Tabel 2

Model IT Benefit

\begin{tabular}{lrrrrrr}
\hline \multicolumn{1}{c}{ Rincian Biaya } & Tahun 1 & Tahun 2 & Tahun 3 & Tahun & Tahun & \multicolumn{1}{c}{ Total } \\
\hline Operasional & - & - & - & - & - & - \\
Penghematan Biaya kertas & 4,20 & 4,41 & 4,63 & 4,86 & 5,10 & 23,20 \\
Penghematan Tinta printer & 24,00 & 25,20 & 26,46 & 27,78 & 29,17 & 132,61
\end{tabular}


Penghematan Jam Lembur

\begin{tabular}{lcccccc}
$\begin{array}{l}\text { karyawan } \\
\begin{array}{l}\text { Penghematan Biaya Listrik dan } \\
\text { Air }\end{array}\end{array}$ & 251,40 & 263,97 & 277,16 & 291,01 & 305,56 & $1.389,10$ \\
$\begin{array}{l}\text { Penghematan Biaya Telepon } \\
\text { dan Internet }\end{array}$ & 260,70 & 273,73 & 287,41 & 301,78 & 316,86 & $1.440,48$ \\
\hline Total & 187,30 & 196,66 & 206,49 & 216,81 & 227,65 & $1.034,91$ \\
\hline
\end{tabular}

Catatan: Biaya (x Rp. 1 juta)

\section{Value Linking, Value Acceleration dan Value Restructing}

Value linking merupakan analisis dalam mengevaluasi secara finasial dan dihubungkan dengan faktor-faktor dalam domain bisnis dan domain teknologi yang memberikan dampak terhadap peningkatan kinerja dan produktifitas serta penurunan biaya ataupun peningkatan pendapatan pada bagian lain dengan adanya implementasi Navision tersebut.

Value Acceleration digunakan untuk mengevaluasi secara finansial setiap percepatan waktu dari manfaat dan biaya karena hubungan sebab akibat yang terjadi pada dua departemen atau fungsi yang terkait.

Value Restructuring terjadi karena dalam perusahaan terjadi perubahan atau perombakan sturtur organisasi, di mana terdapat karyawan yang mengalami pergeseran jabatan. Pergeseran itu terjadi dikarenakan terdapat beberapa karyawan yang tidak berkompeten dalam menggunakan sistem baru yang diimplementasikan oleh perusahaan.

Berikut hasil analisis manfaat nilai ekonomis dari Value linking, Value Acceleration, dan Value restructuring (Tabel 3).

Tabel 3

Manfaat Nilai Ekonomis Value linking, Value Acceleration, dan Value restructuring

\begin{tabular}{lrrrrr}
\hline \multicolumn{1}{c}{ Keterangan } & Tahun 1 & Tahun 2 & Tahun 3 & Tahun 4 & \multicolumn{1}{c}{ Tahun 5 } \\
\hline Value Linking & $1.941,41$ & $2.038,48$ & $2.140,40$ & $2.247,41$ & $2.359,77$ \\
Value Acceleration & 446,40 & 468,72 & 492,15 & 516,75 & 542,58 \\
Value Restructuring & 362,40 & 380,52 & 399,54 & 419,51 & 440,48 \\
\hline Total & $\mathbf{2 . 7 5 0 , 2 1}$ & $\mathbf{2 . 8 8 7 , 7 2}$ & $\mathbf{3 . 0 3 2 . 0 9}$ & $\mathbf{3 . 1 8 3 , 6 7}$ & $\mathbf{3 . 3 4 2 , 8 3}$
\end{tabular}

Catatan: biaya ( x Rp. 1 juta )

Hasil kuantitatif lembar dampak ekonomis sederhana dapat dilihat pada Tabel 4 di bawah ini:

Tabel 4

Lembar Dampak Ekonomis Sederhana

Lembar Dampak Ekonomis

A. Biaya investasi pengembangan sistem

970

B. Arus Kas: periode 5 kali 12 bulan atas implementasi aplikasi Navision

\begin{tabular}{|c|c|c|c|c|c|c|}
\hline & Tahun 1 & Tahun 2 & Tahun 3 & Tahun 4 & Tahun 5 & Total \\
\hline $\begin{array}{l}\text { Manfaat nilai } \\
\text { ekonomis }\end{array}$ & $2.750,21$ & $2.887,72$ & 3.032 .09 & $3.183,67$ & $3.342,83$ & \\
\hline (+)Pengurangan & 727,60 & 763,97 & 802,15 & 842,24 & 884,34 & \\
\hline
\end{tabular}


biaya
(=)Perolehan
$3.477,81$
$3.651,69$
$3.834,24$
$4.025,91$
$4.227,17$
(-) Biaya berjalan
$(=)$ Arus kas
788,40
815,22
843,38
872,95
903,99
bersih
C. $\quad$ ROI Sederhana $=$ Arus kas 5 tahun/jumlah tahun/biaya pengembangan sistem *100\%
$(14.992 .880 .000 / 5 / 970.000 .000) * 100 \%=\underline{\mathbf{3 0 9 , 1 3 \%}}$
Scoring economic impact
Score Simple ROI
1. Zero to less
2. $1 \%$ to $299 \%$
3. $300 \%$ to $499 \%$
4. $500 \%$ to $699 \%$
5. $700 \%$ to $899 \%$
6. Over

Catatan: biaya ( x Rp. 1 juta )

\section{Penilaian Faktor-Faktor Domain Bisnis dan Domain Teknologi}

Penilaian Faktor Domain Bisnis (Tabel 5) didasarkan pada kesesuaian antara application Navision dengan kondisi pada PT. FLN. Tujuan kuisioner ini adalah memperoleh skor dan faktor domain bisnis terhadap aplikasi yang di implementasikan. Terdapat banyak values dan risk yang tidak tampak pada domain bisnis. Dengan penyebaran kuisioner ini bertujuan agar kita dapat melingetahui dengan jelas berapa total skor yang dapat kita peroleh dari tiap - tiap faktor domain teknologi. Faktor faktor ini menyediakan konteks strategi teknologi di antara alternatif investasi teknologi informasi yang dapat dilihat pada Tabel 6 di bawah ini:

Tabel 5

Penilaian Faktor Domain Bisnis

\begin{tabular}{|c|c|c|c|c|c|c|c|}
\hline \multirow{2}{*}{$\begin{array}{l}\text { Faktor-Faktor } \\
\text { Domain Bisnis }\end{array}$} & \multicolumn{4}{|c|}{$\begin{array}{c}\text { Skor } \\
\text { Responden } \\
\end{array}$} & \multirow{2}{*}{$\begin{array}{l}\text { Total } \\
\text { Skor }\end{array}$} & \multirow{2}{*}{$\begin{array}{c}\text { Skor } \\
\text { Rata-Rata }\end{array}$} & \multirow{2}{*}{$\begin{array}{c}\text { Pembulatan } \\
\text { Skor }\end{array}$} \\
\hline & 1 & 2 & 3 & 4 & & & \\
\hline Strategic Match & 4 & 4 & 4 & 3 & 15 & 3,75 & 4 \\
\hline Competitive Advantage & 4 & 1 & 1 & 2 & 8 & 2 & 2 \\
\hline Management Information Support & 4 & 4 & 4 & 3 & 15 & 3,75 & 4 \\
\hline Competitive Response & 5 & 4 & 3 & 3 & 15 & 3,75 & 4 \\
\hline Project or Organizational Risk & 2 & 1 & 1 & 1 & 5 & 1,25 & 1 \\
\hline
\end{tabular}

Tabel 6

Penilaian Faktor Domain Teknologi

\begin{tabular}{|c|c|c|c|c|c|c|c|}
\hline \multirow{2}{*}{ Faktor-Faktor Domain Teknologi } & \multicolumn{4}{|c|}{$\begin{array}{c}\text { Skor } \\
\text { Responden } \\
\end{array}$} & \multirow[t]{2}{*}{ Total skor } & \multirow{2}{*}{$\begin{array}{c}\text { Skor rata- } \\
\text { rata }\end{array}$} & \multirow{2}{*}{$\begin{array}{c}\text { Pembulatan } \\
\text { skor }\end{array}$} \\
\hline & 1 & 2 & 3 & 4 & & & \\
\hline Strategic IS Architecture & 3 & 3 & 4 & 4 & 14 & 3.5 & 4 \\
\hline Definitional Uncertainty & 2 & 2 & 1 & 3 & 8 & 2 & 2 \\
\hline
\end{tabular}


Technical Uncertainty

- Keterampilan yang dibutuhkan

- Ketergantungan perangkat keras

- Ketergantungan piranti lunak

- Piranti Lunak Aplikasi

IS Infrastructure Risk

$\begin{array}{lll}4 & 4 & 3 \\ 2 & 2 & 3 \\ 4 & 3 & 4 \\ 3 & 4 & 3 \\ 3 & 3 & 2\end{array}$

$\begin{array}{rrr}15 & 3,75 & 4 \\ 9 & 2,25 & 2 \\ 16 & 4 & 4 \\ 13 & 3,25 & 3 \\ 12 & 3 & 3\end{array}$

\section{Formulasi Akhir Dalam Information Economics Scorecard}

Setelah dilakukan perhitungan ROI dan penilaian nilai dan resiko dalam domain bisnis dan domain teknologi maka selanjutnya akan memasukkan nilai resiko serta hasil ROI tersebut kedalam Information Economics Scorecard. Factor pada Information Economics Scorecard tersebut didapat dari bobot nilai, seperti bobot nilai yang ada di nilai proyek maksimum pada tabel di bawah.

Tabel 6

Information Economics Scorecard

\begin{tabular}{|c|c|c|c|c|c|c|c|c|c|c|c|}
\hline \multirow{2}{*}{$\begin{array}{l}\text { Evaluator } \\
\text { Factor }\end{array}$} & \multicolumn{6}{|c|}{ Business Domain } & \multicolumn{4}{|c|}{$\begin{array}{l}\text { Technologi } \\
\text { Domain }\end{array}$} & \multirow[t]{2}{*}{$\begin{array}{c}\text { Weighted } \\
\text { Score }\end{array}$} \\
\hline & ROI & SM & CA & MI & CR & OR & SA & DU & TU & IR & \\
\hline & 4 & 5 & 2 & 2 & 3 & 3 & -1 & 0 & -1 & -1 & \\
\hline $\begin{array}{l}\text { Business } \\
\text { Domain }\end{array}$ & 3 & 4 & 2 & 4 & 4 & 1 & & & & & \\
\hline & & & & & & & 4 & 2 & 3 & 3 & \\
\hline $\begin{array}{l}\text { Weighted } \\
\text { Value }\end{array}$ & 12 & 20 & 4 & 8 & 12 & 3 & -4 & 0 & -3 & -3 & 49 \\
\hline
\end{tabular}

Keterangan:

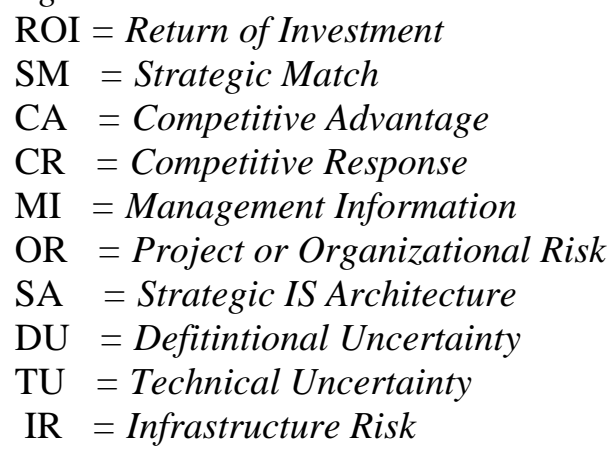

Dari data diatas, total skor untuk Domain Business adalah 59, sedangkan untuk Domain Technology adalah -10. Jadi, total dari keseluruhan digabung dalam Information Economic Scorecard yaitu 49 yang berarti cukup baik (total skor Domain business - total skor Domain Technology). Skor tersebut akan dimasukkan ke dalam skala Likert dengan nilai maksimum dan nilai minimum dari Gambar 4. Dari tabel tersebut didapatkan skor maksimum adalah 120 poin dan skor minimum adalah 8 poin. Besarnya pengaruh dari application Navision bagi PT. FLN dapat dilihat pada gambar 2 skala Likert berikut ini: 


\begin{tabular}{c|c|c|c|c|c|c|} 
Sangat Buruk & Buruk & Kurang & & Cukup & Baik & Sangat Baik \\
8 & 20 & 40 & $\mathbf{4 9}$ & 60 & 80 & 120
\end{tabular}

Gambar 4. Skala Likert Economic Scorecard dari Navision.

\section{PENUTUP}

\section{Simpulan}

Dari analisis yang dilakukan terhadap investasi aplikasi Navision pada PT. FLN, kesimpulan yang didapatkan antara lain: (1) Aplikasi Navision membantu perusahaan dalam pembuatan laporan dan pengiriman data antar bagian serta kantor cabang; (2) Dengan menggunakan traditional cost an benefit analysis maka diperoleh ROI sebesar - 4.19\%. Hal ini memperlihatkan tidak adanya keuntungan finansial langsung sehingga proyek kelihatan merugi apalagi ROI bernilai negatif; (3) Pada tahap kedua yang merupakan perluasan dari cost and benefit analysis, yaitu adanya value linking, value acceleration dan value rectructuring, diperoleh nilai ROI sebesar 309.13\%. Dimana terdapat peningkatan sebesar 313.32\%; (4) Dalam perhitungan Information Economics Scorecard maka didapat nilai sebesar 49 yang digunakan dalam pengukuran skala Likert sehingga dapat disimpulkan bahwa pengimplementasian aplikasi Navision bernilai cukup.

\section{Saran}

Dari hasil penelitian yang dilakukan, penulis memberikan beberapa saran terhadap penerapan metode Information Economics untuk menilai investasi teknologi informasi: (1) Hasil penelitian dari implementasi Navision pada PT. FLN ini dapat digunakan sebagai refrensi yang bermanfaat bagi penentuan investasi proyek teknologi informasi yang lain yang akan dikembangkan oleh PT. FLN; (2) Agar kinerja sistem ini dapat lebih meningkat, sebaiknya divisi IT harus terus memperhatikan kesesuaian sistem khususnya divisi produksi dengan aktivitas perusahaan, agar dapat dilakukannya perbaikan-perbaikan terhadap aplikasi Navision, sehingga dapat terus mendukung kegiatan operasional perusahaan; (3) Berdasarkan penelitian ini dapat dinilai bahwa implementasi aplikasi Navision sudah cukup mendukung proses bisnis bagian produksi pada PT. FLN, namun perlu dilakukan berbagai inovasi dan penambahan berdasarkan kebutuhan yang berkembang saat ini; (4) Perlu adanya pelatihan pada karyawan khususnya pada bagian produksi sehingga aplikasi ini dapat dimanfaatkan secara maksimal untuk mendukung kegiatan operasional pada divisi produksi di PT. FLN.

\section{DAFTAR PUSTAKA}

Parker, Marlyn M., and Benson, Robert J., (1988). Information Economics, Linking Business Performance to Information Technology. New Jersey: Prentice Hall. 